\title{
KNOWLEDGE, ALTITUDE AND PRACTICE OF NURSES TOWARDS NEONATAL SEPSIS IN DUHOK GOVERNORATE
}

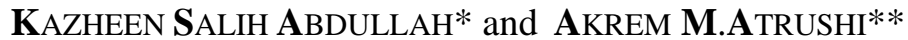 \\ "Dept. of pediatrics, College of Medicine, University of Duhok, Kurdistan Region-Iraq. \\ ${ }^{* *}$ Dept. of pediatrics, College of Nursing, University of Duhok, Azadi Heart Surgery Centre, \\ Kurdistan Region-Iraq.
}

(Received: October 31, 2019; Accepted for Publication: December 10, 2019)

\begin{abstract}
Background and Objectives: Neonatal sepsis is a significant cause of morbidity and mortality of hospitalized newborns and premature infants. The aim of this study was to assess nurses' knowledge, attitude and practice towards neonatal sepsis in Duhok governorate.

Methods: In this cross-sectional study, a total of 171 nurses of both genders with different educational levels and working experiences who are dealing with neonates of public hospital were conventionally included. The data required for the present study were collected through investigator-administered self-reported technique between June 2018 and November 2018. In order to determine the face validity of the questionnaire the researcher distributed copies to experts in the medical, nursing pediatric and research departments to have their opinion about the items. The questionnaire was sent to (8) who had experience of more than 5 year in their field. The reliability was tested by using Cronbach's Alpha to ascertain reliability and consistency of the survey. Cronbach's Alpha for the survey instrument was $(0.71)$ respectively indicating acceptable level of reliability and consistency. The descriptive purposes of the study were determined in mean and standard deviation or frequency and percentage. The comparison of general knowledge information among nurses with different educational levels was examined in Pearson Chi-squared test or Fishers' exact test. The P-value of less than 0.05 was considered statistically significant difference. The statistical calculations were performed by Statistical Package for Social Sciences 24 (SPSS 24; IBM Corp; USA).

Results: The median age and working experience of the nurses were 26.0 and 4.0 years, respectively. Most of the nurses were females $(\mathbf{7 5 . 4 \%})$. Most of the nurses had poor knowledge about general information of neonatal sepsis such as neonatal sepsis definition $(69.0 \%)$, its manifestations $(63.7 \%)$. However, most of the nurses had the positive attitudes. In addition, most of the nurses did always or sometimes the intervention, such as monitoring neonate's general condition $(66.1 \%)$, measuring temperature $(\mathbf{8 5 . 9 \%})$, monitoring vital signs $(52.6 \%)$,

Conclusions: The present study showed that the nurses had poor knowledge about neonatal sepsis despite they had the positive attitude with most time the correct intervention.(I used the term of intervention instead of practice which I mean their performances and practices, I used the term for the same purpose.)
\end{abstract}

KEYWORDS: neonatal sepsis, knowledge, attitude, practice, nurses

\section{INTRODUCTION}

$\mathbf{N}$ eonatal sepsis is a clinical syndrome identified by systemic signs of infection and bacteremia in the neonatal phase (Shah\& Padbury 2014). Sepsis, also defined as septicemia, is a toxic condition caused by the spread of invading organisms, or by their products, through the bloodstream or in other tissue in the body. Sepsis is not only an infection, but it is also includes a spectrum of symptoms of systemic inflammatory response syndrome (SIRS) to septic shock (Goldstein et al., 2005).Neonatal sepsis happens within the first 30 days of life, although some late-onset sepsis has been described within the first 90 days of life, particularly when related to prematurity (Van Herk et al., 2016).

Neonatal sepsis remains one of the leading causes of morbidity and mortality both among term and preterm infants ( CamachoGonzalez et al.,2013).Although advances in 
neonatal care have improved survival and reduced complications in preterm infants, sepsis still contributes significantly to mortality and morbidity among very-low-birth-weight (VLBW, <1500 g) infants in Neonatal Intensive Care Units (NICUs) (Hornik et al., 2012). The estimated global burden for neonatal sepsis was 2,202 (95\% CI: 1,099$4,360)$ per 100,000 live births, with mortality between $11 \%$ and $19 \%$ (Fleischmann-Struzek et al., 2018). In recent years, there is considerable reduction in childhood mortality carried out worldwide (Wang et al., 2013).

Every year 2.6 million neonates die; three fourths of these deaths happen in the first week of life, and almost all (99\%) in low- and middle-income countries (Wang et al., 2013). Sepsis can be prevented largely with prevention of sepsis itself by, early realization, rational antimicrobial therapy and aggressive assistance care ( Bang et al., 1999). A number of pathogens have been related with sepsis in the neonatal duration. The predominant agents are bacterial, but viruses including herpes simplex and enteroviruses have been related sudden neonatal sepsis with high mortality (Verboon-Maciolek et al., 2005).

Neonates with sepsis may present in or develop to septic shock, represented firstly by cardiovascular dysfunction requiring fluid resuscitation or inotropic support (Haque, 2007).. Supportive care of dysfunctional organs is therefore the mainstay of therapy, which might include mechanical ventilation, fluids, vasopressors or inotropes (or both), and blood transfusion. (Du Pont-Thibodeau et al., 2014).

\subsection{Aim of the study}

Aim of my study is to assess knowledge, attitude and practice of nurses towards neonatal sepsis in Duhok governorate.

\section{SUBJECTS AND METHODS}

A descriptive, cross-sectional study conducted to achieve the objectives which includes nurses' knowledge, attitude and practice towards neonatal sepsis during the period from $1^{\text {st }}$ of June 2018 to $30^{\text {th }}$ November 2018 in Duhok governorate. The nonprobability convenience (purposive) sampling method of 171 nurses who have a contact with neonates and neonatal care.The nurses who were in contact with neonates and working in NICU and various pediatric departments at the time of data collection.

Those nurses who were not available during data collection or not-respond following two consecutive contacts were not included in the study. The data required for the present study were collected through investigatoradministered self-reported technique. The data were collected in a semi-structured questionnaire based on the previous studies (Fenton-Jones et al., 2017; Hanaa et al., 2017; Santos et al., 2014).

The questionnaire was presented to the eight experts who had more than 5 years of experience in teaching and evaluation of students' project of medical, nursing pediatric and research departments. Accordingly, the required revision was made on the contents of the assessment form based on the experts' recommendations and comments. The modifications by the researcher were applied. The questionnaire consisted of 4 parts part one: demographic data this part included age, gender, level of education, experience by years, and place of work).part two knowledge of nurses regarding neonatal sepsis, this part included some multiple-choice questions about definition, clinical manifestations, system involved and temperature changes. Part three attitudes this part included information about the nurses' attitudes include neonatal sepsis and practicing of sepsis and practice items included in this were scaled as strongly agree to strongly disagree. Part four, included the nursing practice towards neonatal sepsis were included in this part of the questionnaire and scaled as always to never.

The descriptive purposes of the study were determined in mean and standard deviation or frequency and percentage. The number of correct and incorrect answers on the neonatal sepsis was presented in number and percentage. Attitudes of nurses towards neonatal sepsis in an infant and nursing practice towards neonatal sepsis were presented in number and percentage. The comparison of general knowledge information among nurses with different educational levels was examined in Pearson Chi-squared test or Fishers' exact test. The P-value of less than 0.05 was considered statistically significant 
difference. The statistical calculations were performed by Statistical Package for Social Sciences 24 (SPSS 24; IBM Corp; USA).

Statistical analysis: the data of the present study were prepared, organized entered into the computer through the application of statistical package for social science version 20 which consist of the following:

a. Descriptive data analysis

b. Inferential data analysis.

The approval has been obtained from the ethical committee at directorate of health of Duhok .A written request of agreement was sent to all hospitals for the purpose of facility of data collection, after explaining the aim of the study to nurses verbal and written consent obtained from nurses with emphasizing the confidentiality of the information and data and all nurses who included were totally free to continue or withdraw at any time without any enforcement.

\section{RESULTS}

As in the table (4.1), it is clear that most of nurses $(65.5 \%)$ had work Experience (1- 5) years and most of them were female $(75.4 \%)$. The highest percentage $(66.7 \%)$ was institute nurse. And median age was 26 years.

Table (4.1): General information of nurses

\begin{tabular}{lll}
\hline \multicolumn{1}{c}{ Characteristics of Nurses } & Frequency & Percentage \\
\hline Age (Year); Median/Interquartile Range & 26.00 & 9.0 \\
Range: 21-62 years & & \\
\hline Working experience (Year); Median/Interquartile Range & 4.0 & 6.0 \\
1-5 Years & 112 & 65.5 \\
6-10 Years & 24 & 14.0 \\
$11-15$ Years & 9 & 5.3 \\
16 years and more & 26 & 15.2 \\
\hline Gender & & \\
Male & 42 & 24.6 \\
Female & 129 & 75.4 \\
\hline Education & & 21.1 \\
High School and Under & 36 & 66.7 \\
Nurse Institute & 114 & 12.3 \\
College Nurse & 21 & \\
\hline Frequency and percentage were calculated for gender and education and median and interquartile range for age \\
and working experience.
\end{tabular}

Table (4.2) shows that the nurses answered incorrectly the questions about earlier born premature, are at greater risk, body temperature is a red flag, definition of neonatal sepsis and neonatal sepsis`s signs, in (93.6\%), (89.5\%),
(69.0\%), (63.7\%), respectively. While $(57.3 \%)$ most of them answered correctly the question about clinical features related to neonatal sepsis.

Table (4.2): General informaiton of nurses towards neonatal sepsis in an infant

\begin{tabular}{lcc}
\hline \multicolumn{1}{c}{ General Information } & \multicolumn{1}{c}{ Frequency Distribution F(\%) } \\
\cline { 2 - 3 } Neonatal sepsis refers to sepsis in child & Correct & $53(31.0)$ \\
\hline Neonatal sepsis generally manifests as & $62(36.3)$ & $118(69.0)$ \\
\hline Premature infants are at greater risk of sepsis if born earlier than & $11(6.4)$ & $109(63.7)$ \\
\hline Clinical features of neonatal sepsis frequently involve changes to & $98(57.3)$ & $73(42.7)$ \\
\hline In child with suspected sepsis temperature is a red flag if it is & $18(10.5)$ & $153(89.5)$ \\
\hline
\end{tabular}

According to the table (4.3) revealed that the nurses had a strong attitude towards their feeling about recognizing neonatal sepsis and other questions regarding neonatal sepsis. 
Table (4.3): Nurses attitudes towards neonatal sepsis

\begin{tabular}{|c|c|c|c|c|c|}
\hline Attitudes towards neonatal sepsis & $\begin{array}{l}\text { Strongly } \\
\text { Agree }\end{array}$ & Agree & neutral & Disagree & $\begin{array}{l}\text { Strongly } \\
\text { Disagree }\end{array}$ \\
\hline $\begin{array}{l}\text { I feel Contented recognizing when a patient is experiencing } \\
\text { sepsis }\end{array}$ & $153(89.5)$ & $7(4.1)$ & $3(1.8)$ & $5(2.9)$ & $3(1.8)$ \\
\hline $\begin{array}{l}\text { I feel comfortable recognizing when a patient is experiencing } \\
\text { septic shock }\end{array}$ & $158(92.4)$ & $3(1.8)$ & $2(1.2)$ & $1(0.6)$ & $7(4.1)$ \\
\hline $\begin{array}{l}\text { I feel comfortable notifying a physician/nurse practitioner that } \\
\text { one of my patient is experiencing sepsis based solely on my } \\
\text { assessment of the patient }\end{array}$ & $51(29.8)$ & $34(19.9)$ & $42(24.6)$ & $19(11.1)$ & $25(14.6)$ \\
\hline $\begin{array}{l}\text { If I have a patient, I feel this is a high priority patient } \\
\text { necessitating immediate action by physician/nurse } \\
\text { practitioner }\end{array}$ & $115(67.3)$ & $33(19.3)$ & $10(5.8)$ & $5(2.9)$ & $8(4.7)$ \\
\hline $\begin{array}{l}\text { If I have a patient, I feel comfortable calling or initiating the } \\
\text { chain of command if the patient's physician/nurse } \\
\text { practitioner is not ordering appropriate and safe } \\
\text { interventions. }\end{array}$ & $101(59.1)$ & $26(15.2)$ & $14(8.2)$ & $15(8.8)$ & $15(8.8)$ \\
\hline $\begin{array}{l}\text { I know what to do with a patient in septic shock or sepsis } \\
\text { until the additional support. }\end{array}$ & $67(39.2)$ & $36(21.1)$ & $28(16.4)$ & $26(15.2)$ & $14(8.2)$ \\
\hline
\end{tabular}

Table (4.4) shows that $(88.3 \%)$ of nurses always using antipyretics, also (94.7\%) always administer IV fluid replacement as ordered , $(73.1 \%)$ always Elevate affected extremities with edema once in a while for ineffective tissue perfusion. contented

Table (4.4): nursing practice of neonatal sepsis

\begin{tabular}{|c|c|c|c|c|c|}
\hline \multirow[t]{2}{*}{ Nursing practice towards neonatal sepsis } & \multicolumn{5}{|c|}{ Frequency Distribution $\mathrm{f}(\%)$} \\
\hline & Always & Sometimes & Occasionally & Rarely & Never \\
\hline \multicolumn{6}{|c|}{ Nursing Interventions to fever in an infant sepsis } \\
\hline Monitoring neonate's general condition & $94(55.0)$ & $19(11.1)$ & $15(8.8)$ & $2(1.2)$ & $41(24.0)$ \\
\hline measuring temperature & $117(68.4)$ & $30(17.5)$ & $12(7.0)$ & $3(1.8)$ & $9(5.3)$ \\
\hline monitor vital signs & $71(41.5)$ & $19(11.1)$ & $12(7.0)$ & $1(0.6)$ & $68(39.8)$ \\
\hline $\begin{array}{l}\text { Ensure that all equipment used for infant is } \\
\text { sterile, ........... }\end{array}$ & $123(71.9)$ & $14(8.2)$ & $13(7.6)$ & $15(8.8)$ & $6(3.5)$ \\
\hline administer antipyretics as ordered & $151(88.3)$ & $5(2.9)$ & $5(2.9)$ & $4(2.3)$ & $6(3.5)$ \\
\hline \multicolumn{6}{|c|}{ Practice of nurses on fluid volume deficit } \\
\hline Monitor and record vital signs & $87(50.9)$ & $13(7.6)$ & $5(2.9)$ & & $66(38.6)$ \\
\hline $\begin{array}{l}\text { Provide oral care by moistening lips and skin } \\
\text { care by providing daily bath }\end{array}$ & $102(59.6)$ & $19(11.1)$ & $13(7.6)$ & $13(7.6)$ & $24(14.0)$ \\
\hline Administer IV fluid replacement as ordered & $162(94.7)$ & $3(1.8)$ & $1(0.6)$ & & $5(2.9)$ \\
\hline $\begin{array}{l}\text { Administer antipyretic drugs if patient has fever } \\
\text { as ordered }\end{array}$ & $157(91.8)$ & $7(4.1)$ & $19(0.6)$ & $2(1.2)$ & $4(2.3)$ \\
\hline \multicolumn{6}{|c|}{ Practice of nurses on ineffective tissue perfusion } \\
\hline Note quality and strength of peripheral pulses. & $37(21.6)$ & $17(9.9)$ & $8(4.7)$ & $13(7.6)$ & $96(56.1)$ \\
\hline Assess respiratory rate, depth, and quality & $76(44.4)$ & $16(9.4)$ & $6(3.5)$ & $12(7.0)$ & $61(35.7)$ \\
\hline $\begin{array}{l}\text { Assess skin for changes in color, temperature } \\
\text { and moisture. }\end{array}$ & $88(51.5)$ & $27(15.8)$ & $11(6.4)$ & $6(3.5)$ & $39(22.8)$ \\
\hline $\begin{array}{l}\text { Elevate affected extremities with edema once in } \\
\text { a while. }\end{array}$ & $125(73.1)$ & $17(9.9)$ & $9(5.3)$ & $2(1.2)$ & $18(10.5)$ \\
\hline
\end{tabular}


The results of study showed that most of nurses had low level of knowledge, with positive attitudes and good practice

Table (4.5) revealed that the majority of the nurses with baccalaureate degree answered the question items of neonatal sepsis correctly $(66.7 \%)$ compared to only $27.2 \%$ in nurses graduated from institute and $22.2 \%$ in nurses with high school and secondary schools of nursing. While, the majority of the nurses with high school and secondary schools of nursing answered incorrectly to definition of neonatal sepsis $(77.8 \%)$ followed by the nurses with institute $(72.8 \%)$. For the question on neonatal sepsis general manifestation, the three groups High school, institute, college mostly answered incorrectly in (33.3\%), (36.0\%), (42.9\%) respectively. About the early born prematurity have greater risk, all of high school degree nurses answered incorrectly. (60.5\%) of institute nurse, the answer was correct regarding clinical features of neonatal sepsis. Regarding body temperature being a red flag, $(90.4 \%)$ of institute nurses incorrectly answered. The only significant different in relation educational level was in the answer of the question on the definition of neonatal sepsis.

Table (4.5): comparison of General knowledge information among nurses with different educational levels

\begin{tabular}{|c|c|c|c|c|}
\hline \multirow[t]{2}{*}{ Knowledge Items } & \multicolumn{3}{|c|}{ Frequency Distribution F (\%) } & \multirow{2}{*}{$\begin{array}{c}\text { P-Value } \\
\text { (two-Sided) }\end{array}$} \\
\hline & $\begin{array}{l}\text { High School } \\
\text { and Under }\end{array}$ & Institute & College & \\
\hline Neonatal sepsis refers to sepsis in child & & & & $0.001^{*}$ \\
\hline Incorrect & $28(77.8)$ & $83(72.8)$ & 7 (33.3) & \\
\hline Correct & $8(22.2)$ & $31(27.2)$ & $14(66.7)$ & \\
\hline Neonatal sepsis generally manifests as & & & & $0.766^{*}$ \\
\hline Incorrect & $24(66.7)$ & $73(64.0)$ & $12(57.1)$ & \\
\hline Correct & $12(33.3)$ & $41(36.0)$ & $9(42.9)$ & \\
\hline Premature infants are at greater risk of sepsis if born & & & & $0.136^{* \star}$ \\
\hline earlier than & $0(0.0)$ & $9(7.9)$ & $2(9.5)$ & \\
\hline Correct & $36(100)$ & $105(92.1)$ & $19(90.5)$ & \\
\hline \multicolumn{5}{|l|}{ Incorrect } \\
\hline Clinical features of neonatal sepsis frequently involve & & & & $0.478^{*}$ \\
\hline changes to & $18(50.0)$ & $45(39.5)$ & $10(47.6)$ & \\
\hline Incorrect & $18(50.0)$ & $69(60.5)$ & $11(52.4)$ & \\
\hline \multicolumn{5}{|l|}{ Correct } \\
\hline In child with suspected sepsis temperature is a red flag if it & & & & $0.700^{\star *}$ \\
\hline is & $32(88.9)$ & $103(90.4)$ & $18(85.7)$ & \\
\hline Incorrect & $4(11.1)$ & $11(9.6)$ & $3(14.3)$ & \\
\hline Correct & & & & \\
\hline
\end{tabular}

\section{DISCUSSION}

The results showed that the median age of nurses is 26 years old and most of them are female, These results are a little bit different from (Berhe et al., 2016) who mentioned that the median age of nurses was (30), however most of them were female also, similar results founded by (Shauq \& Muala`a 2008), which revealed that most of nurses were female. In this study most of nurses had five years of work experience or less of , which means not enough experience. This is similar to what was reported by (Berhe et al., 2016) that showed most of them didn't have enough experience reported by (international journal of nursing) at 
Ethiopia. Most of nurses had diploma in this study, only some of them had bachelor degree, this is similar to other study reported by (Berhe et al., 2016). But in other study by (Obaid et al., 2015) shown that more than one third of them were secondary school nurses.

The study results revealed that most of the nurses had poor knowledge on newborn care. This result is more or less similar to the study conducted by (Mirkuzie et al.,2014) but its higher than a study by (Ayiasi et al.,2014), that showed, most of nurses had adequate knowledge about newborn care, management of neonatal infections and identifying/stabilizing LBW babies. Most of the nurses who participated in this investigation had incorrect answers on the most items of the neonatal sepsis knowledge. These results are different from those of a study by (Berhe et al., 2016) that showed most of nurses had adequate knowledge on newborn care. Also different to the study by (Obaid et al., 2015) which showed that more than half of the sample had accepted knowledge regarding neonatal sepsis. Also Most of nurses in this study had inadequate knowledge regarding clinical manifestation, etiology, premature risk factors, and its suspected temperature as a red flag. The main reason for the low knowledge in our study was low level of education, this is similar to the study conducted by (NasorTaha,2011) which showed that most of nurses had poor knowledge The nurses with college certificate had a higher percentage of correct answers and low percentage of incorrect answers compared to those nurses with high school and under, this is differ from the result of a study reported by (Kennedy et al.,2004) these showed most of nurses had adequate information about neonatal sepsis. But it's similar to a study by (Obaid et al., 2015) which found that there's significant association between nurses' level of education and knowledge.

Also most of institute nurses failed to answer correctly knowledge questions regarding definition of neonatal sepsis which is different from results of (Boettiger et al., 2017) which revealed no relationships between the level of nursing education and knowledge.

On the contrary these results are similar to (Aiken et al., 2003) who found that nurses' level of education especially baccalaureate or higher decreased the rate of mortality about $5 \%$, Similar findings has been founded in study conducted by (Estabrooks et al., 2005). While other studies by (Tourangeau et al., 2007; Friese et al., 2008) showed results which were similar to those of the studies by (Aiken et al., 2003; Aiken et al., 2008and Estabrooks et al., 2005). These results reinforce the notion that increased knowledge in nursing education plays a vital role in reducing the spread of nosocomial infections and associated death rates, these results supported by studies done in neonatal unit by (Mua'ala \& Wea'am 2010)that concluded significant relationship between nurses' knowledge and level of education.

According to results of this study most of nurses has positive attitude(by counting the question of strongly agreed and agreed) towards recognizing neonatal sepsis regarding answers related attitudes, this is similar to the study conducted by (Boettiger et al., 2017), and a study by (Kamunge, 2013), that showed most of nurses had strongly positive attitudes. Regarding the question if I have a patient, I feel this is a high priority patient necessitating immediate action by physician/nurse practitioner, the results of our study show who strongly agreed this had a long period of experiences in such areas. According to results most nurses from study sample strongly agreed. These results similar to (Stein et al., 2003), Nurses usually displayed better attitudes, And (Sweeney et al., 2013), found that healthcare professionals could improve parents' experiences by better education and knowledge of the situation. In this study all of nurses had positive attitudes regarding neonatal sepsis. Similar to other study reported by (Jeffery et al., 2014). And also similar in some questions to that reported in Egypt by (Hanaa et al., 2017).

In this study the results showed most of nurses measuring temperature always and most of them administer antipyretics as ordered. The results showed that there is a significant difference between educational levels and monitoring neonate's vital signs. This is similar to the results of study conducted in Uganda which showed that appropriate implementation is dependent upon levels of knowledge (Lutwama et al., 2012) 
Most of nurses Monitor and record vital signs always, these results are more or less similar to the study conducted in Vietnam by (Eriksson et al.,2009), Egypt, by (Abd El Fattah et al.,2012) also in in Haryana, India, Khartoum Sudan, Addis Ababa and (Ayiasi et al.,2014; Mirkuzie et al.,2014and Louis et al.,2014). These results are different from Vietnam, which shows the availability of national guideline was not significantly associated with newborn care practice (Eriksson et al., 2009). This finding is consistent with the study done in Addis Ababa (Mirkuzie et al., 2014).

These results are similar to the results of study by (Berhe et al., 2016) most of the participants were having good newborn care practice. Most of nurses always administer IV fluid replacement as ordered, Assess skin for changes in color, temperature and moisture regardless of the level of education. Most of nurses don't note the quality and strength of peripheral pulses this because they think that quality and strength of peripheral pulses is regarded as physicians' job, the majority of college nurses always monitoring neonate's general condition because of their knowledge and job description .Most of High School and under always ensure that all equipment used for infant is sterile, Provide oral care by moistening lips and skin care by providing daily bath this is similar to a study by (Kamunge, 2013) which showed that there is a significant but weak positive correlation between registered nurses' Knowledge and Practice.

\subsection{Conclusions:}

\section{CONCLUSIONS}

The present study showed that the nurses had incorrect responses to most of the knowledge items about neonatal sepsis despite they had the positive attitude with most time the correct practice

Conflict of interest

There are no conflict of interest

\section{REFERENCES}

Abd El Fattah, N., Negawa, A., \& El-Dein, Z. (2012). Assessment of quality of nursing care provided immediately after birth at university hospital. Life Science Journal, 9(4), 2115-2126.

Aiken, L. H., Clarke, S. P., Cheung, R. B., Sloane, D. M., \& Silber, J. H. (2003). Educational levels of hospital nurses and surgical patient mortality. Jama, 290(12), 1617-1623. doi:10.1001/jama.290.12.1617.

Aiken, L. H., Clarke, S. P., Sloane, D. M., Lake, E. T., \& Cheney, T. (2008). Effects of hospital care environment on patient mortality and nurse outcomes. The Journal of nursing administration, $\quad 38(5), \quad 223$. doi: 10.1097/01.NNA.0000312773.42352.d7

Ayiasi, R. M., Criel, B., Orach, C. G., Nabiwemba, E., \& Kolsteren, P. (2014). Primary healthcare worker knowledge related to prenatal and immediate newborn care: a cross sectional study in Masindi, Uganda. BMC health services research, 14(1), 65. doi:10.1186/1472-6963-14-65

Bang, A. T., Bang, R. A., Baitule, S. B., Reddy, M. H., \& Deshmukh, M. D. (1999). Effect of home-based neonatal care and management of sepsis on neonatal mortality: field trial in rural India. The lancet, 354(9194), 19551961. doi:10.1016/s0140-6736(99)03046-9

Berhe, A. K., Tinsae, F., \& Gebreegziabher, G. (2017). Knowledge and practice of immediate newborn care among health care providers in eastern zone public health facilities, Tigray, Ethiopia, 2016. $B M C$ pediatrics, 17(1), 157. doi:10.1186/s12887017-0915-8

Boettiger, M., Tyer-Viola, L., \& Hagan, J. (2017). Nurses' Early Recognition of Neonatal Sepsis. Journal of Obstetric, Gynecologic \& Neonatal Nursing, 46(6), 834-845. 10.1016/j.jogn.2017.08.007.

Camacho-Gonzalez, A., Spearman, P. W., \& Stoll, B. J. (2013). Neonatal infectious diseases: evaluation of neonatal sepsis. Pediatric Clinics of North America, 60(2), 367. doi: 10.1016/j.pcl.2012.12.003

Du Pont-Thibodeau, G., Joyal, J. S., \& Lacroix, J. (2014). Management of neonatal sepsis in term newborns. F1000prime reports, 6. doi:10.12703/p6-67

Eriksson, L., Nga, N. T., Målqvist, M., Persson, L. A., Ewald, U., \& Wallin, L. (2009). Evidence-based practice in neonatal health: knowledge among primary health care staff in northern Viet Nam. Human Resources for Health, 7(1), 36. doi:10.1186/1478-4491-736. 
Estabrooks, C. A., Midodzi, W. K., Cummings, G. G., Ricker, K. L., \& Giovannetti, P. (2005). The impact of hospital nursing characteristics on 30-day mortality. Nursing research, 54(2), 74-84.

Fenton-Jones, M., Cannon, A., \& Paul, S. P. (2017). Recognition and nursing management of sepsis in early infancy. Emergency Nurse (2014+), 25(6),

23. doi:10.7748/en.2017.e1704.

Fleischmann-Struzek, C., Goldfarb, D. M., Schlattmann, P., Schlapbach, L. J., Reinhart, K., \& Kissoon, N. (2018). The global burden of paediatric and neonatal sepsis: a systematic review. The Lancet Respiratory Medicine, 6(3), 223-230. doi:10.1016/s22132600(18)30063-8

Friese, C. R., Lake, E. T., Aiken, L. H., Silber, J. H., \& Sochalski, J. (2008). Hospital nurse practice environments and outcomes for surgical oncology patients. Health services research, 43(4), 1145-1163. doi:10.1111/j.1475-6773.2007.00825.x

Goldstein, B., Giroir, B., \& Randolph, A. (2005). International pediatric sepsis consensus conference: definitions for sepsis and organ dysfunction in pediatrics. Pediatric critical care medicine, 6(1), 2-8. 10.1097/01.PCC.0000149131.72248.E6

Hanaa M., Ahmed, H. I. E. S. (2017). KNOWLEDGE AND IDENTIFICATION OF SEPSIS AMONG PEDIATRIC NURSES AT NEONATAL INTENSIVE CARE UNITS. Innovative Journal of Medical and Health Science, 7(3). https://doi.org/10.15520/ijmhs.2017.vol7.iss 3.163.

Haque, K. N. (2007). Defining common infections in children and neonates. Journal of Hospital Infection, 65, 110-114.

Hornik, C. P., Fort, P., Clark, R. H., Watt, K., Benjamin Jr, D. K., Smith, P. B., .. \& Cohen-Wolkowiez, M. (2012). Early and late onset sepsis in very-low-birth-weight infants from a large group of neonatal intensive care units. Early human development, $\quad 88, \quad$ S69-S74. doi:10.1016/s0378-3782(12)70019-1 .

Jeffery, A. D., Mutsch, K. S., \& Knapp, L. (2014). Knowledge and recognition of SIRS and sepsis among pediatric nurses. Pediatric nursing, 40(6).

Kamunge, E. W. (2013). Exploring knowledge, attitudes and practices of registered nurses regarding the spread of nosocomial infections.

Kennedy, A. M., Elward, A. M., \& Fraser, V. J. (2004). Survey of knowledge, beliefs, and practices of neonatal intensive care unit healthcare workers regarding nosocomial infections, central venous catheter care, and hand hygiene. Infection Control \& Hospital Epidemiology, 25(9), 747-752. DOI: 10.1086/502471

Louis, D., Kumar, P., \& Gupta, A. (2013). Knowledge and practices of healthcare providers about essential newborn care and resuscitation in a district of Haryana. Journal of the Indian Medical Association, 111(2), 114-117.

Lutwama, G. W., Roos, J. H., \& Dolamo, B. L. (2012). A descriptive study on health workforce performance after decentralisation of health services in Uganda. Human resources for health, 10(1), 41. doi:10.1186/1478-4491-10-41

Mirkuzie, A. H., Sisay, M. M., Reta, A. T., \& Bedane, M. M. (2014). Current evidence on basic emergency obstetric and newborn care services in Addis Ababa, Ethiopia; a cross sectional study. BMC pregnancy and childbirth, 14(1), 354. doi:10.1186/14712393-14-354

Mua'ala, E. G., \& Wea'am N, K. (2010). Assessment of Nurses' Knowledge toward Children with Guillain-Barre Syndrome at Pediatric Hospitals in Baghdad City. nursing national Iraqi specility, (3), 1-10.

NasorTaha, A. Faiza.2011. Assessment of knowledge, Attitude and Practices of nurse midwives towards immediate care of the newbornIn Khartoum state teaching hospitals. Journal of American Science, 9(9).

OBAID, B.K., HUSSEIN, A.\& NOORI, K.A(2014). Nurses' Knowledge Concerning Neonatal Sepsis In Neonatal Intensive Care Units At Pediatric Teaching Hospitals In Baghdad City .Asian Academic Research Journal of Multidisciplinary

Santos, A. P. D. S., Silva, M. D. L. C. D., Souza, N. L. D., Mota, G. M., \& França, D. F. D. (2014). Nursing diagnoses of newborns with sepsis in a Neonatal Intensive Care Unit. Revista latino-americana de enfermagem, 22(2), 255-261. doi:10.1590/01041169.3101.2410

Shah, B. A., \& Padbury, J. F. (2014). Neonatal sepsis: an old problem with new insights. 
Virulence, 5(1),

$170-178$. doi:10.4161/viru.26906.

Shauq,H, A., Muala`a, G.E. (2008) .Assessment Of The Pediatric Nurses` Knowledge About The Nosocomial Infection In The Neonatal Intensive Care Unit Of Baghdad Pediatric Teaching Hospitals. ResearchGate. Available from:3(7)July 2016

Stein, A. D., Makarawo, T. P., \& Ahmad, M. F. R. (2003). A survey of doctors' and nurses' knowledge, attitudes and compliance with infection control guidelines in Birmingham teaching hospitals. Journal of hospital infection, 54(1), 68-73. doi:10.1016/s01956701(03)00074-4

Sweeney, F., M Viner, R., Booy, R., \& Christie, D. (2013). Parents' experiences of support during and after their child's diagnosis of $\mathrm{M}$ eningococcal D isease. Acta Paediatrica, 102(3), e126-e130. doi:10.1111/apa.12112.

Tourangeau, A. E., Doran, D. M., Hall, L. M., O'Brien Pallas, L., Pringle, D., Tu, J. V., \& Cranley, L. A. (2007). Impact of hospital nursing care on 30-day mortality for acute medical patients. Journal of advanced nursing, 57(1), 32-44. doi:10.1111/j.13652648.2006.04084.x

Van Herk, W., Stocker, M., \& van Rossum, A. M. (2016). Recognising early onset neonatal sepsis: an essential step in appropriate antimicrobial use. Journal of Infection, 72, S77-S82. doi:10.1016/j.jinf.2016.04.026

Verboon-Maciolek, M. A., Krediet, T. G., Gerards, L. J., Fleer, A., \& van Loon, T. M. (2005). Clinical and epidemiologic characteristics of viral infections in a neonatal intensive care unit during a 12-year period. The Pediatric infectious disease journal, 24(10), 901-904. doi:10.1097/01.inf.0000180471.03702.7f

Wang, H., Liddell, C. A., Coates, M. M., Mooney, M. D., Levitz, C. E., Schumacher, A. E., ... \& Sandar, L. (2014). Global, regional, and national levels of neonatal, infant, and under-5 mortality during 1990-2013: a systematic analysis for the Global Burden of Disease Study 2013. The Lancet, 384(9947), 957-979. doi:10.1016/s0140- 